\title{
Sertraline Pharmacokinetics in HIV-Infected and Uninfected Children, Adolescents, and Young Adults
}

\author{
Nathan John Hanan ${ }^{1}$, Mary Elizabeth Paul ${ }^{2}$, Yanling Huo ${ }^{3}$, Suad Kapetanovic ${ }^{4}$, \\ Elizabeth Smith ${ }^{5}$, George Siberry ${ }^{6}$, Pim Brouwers ${ }^{7}$, Bobbie Graham ${ }^{8}$, \\ Benjamin Johnston ${ }^{8}$, Edmund V. Capparelli ${ }^{1,9}$ and Brookie M. Best ${ }^{1,9 *}$ \\ On behalf of the IMPAACT P1080 Protocol Team
}

OPEN ACCESS

Edited by:

Bernd Meibohm,

University of Tennessee Health

Science Center (UTHSC),

United States

Reviewed by:

Jacob Tyler Brown

University of Minnesota, United States Michael Lloyd Christensen, University of Tennessee Health

Science Center (UTHSC),

United States

Stephanie Laeer,

Heinrich Heine Universität Düsseldorf,

Germany

Shirley Seo,

United States Food and Drug

Administration, United States

*Correspondence:

Brookie M. Best

brookie@ucsd.edu

Specialty section:

This article was submitted to

Obstetric and Pediatric Pharmacology,

a section of the journal

Frontiers in Pediatrics

Received: 20 September 2018

Accepted: 15 January 2019

Published: 06 February 2019

Citation:

Hanan NJ, Paul ME, Huo Y Kapetanovic S, Smith E, Siberry G,

Brouwers P, Graham B, Johnston B,

Capparelli EV and Best BM (2019)

Sertraline Pharmacokinetics in HIV-Infected and Uninfected Children,

Adolescents, and Young Adults.

Front. Pediatr. 7:16.

doi: 10.3389/fped.2019.00016
${ }^{1}$ Department of Pediatrics-Rady Children's Hospital San Diego, University of California, San Diego, San Diego, CA, United States, ${ }^{2}$ Department of Pediatrics, Baylor College of Medicine, Houston, TX, United States, ${ }^{3}$ Center for Biostatistics in AIDS Research, Harvard T.H. Chan School of Public Health, Boston, MA, United States, ${ }^{4}$ Department of Psychiatry, University of Southern California, Los Angeles, CA, United States, ${ }^{5}$ Maternal, Adolescent, and Pediatric Research Branch, National Institute of Allergy and Infectious Diseases, Bethesda, MD, United States, ${ }^{6}$ Maternal and Pediatric Infectious Disease Branch, Eunice Kennedy Shriver National Institute of Child Health and Human Development, Bethesda, MD, United States, ${ }^{7}$ Division of AIDS Research, National Institute of Mental Health, National Institutes of Health, Bethesda, MD, United States, ${ }^{8}$ Frontier Science and Technology Research Foundation, Buffalo, NY, United States, ${ }^{9}$ Skaggs School of Pharmacy and Pharmaceutical Sciences, University of California, San Diego, La Jolla, CA, United States

Objective: Due to potential disease and drug interactions, the appropriate sertraline starting dose and titration range may require adjustment in pediatric patients living with HIV. This is the first report of sertraline pharmacokinetics in HIV-infected youth.

Methods: IMPAACT P1080 was a multicenter pilot study describing psychiatric medication pharmacokinetics in HIV-infected and uninfected youth. Participants were stable on sertraline, $>6$ to $<25$ years old, and (1) HIV-uninfected (HIV(-)), (2) HIVinfected taking efavirenz (EFV), or (3) HIV-infected taking boosting ritonavir/protease inhibitor (PI/r). Sampling occurred at pre-dose, 2, 4, 6, 12, and 24-h post-dose. Analyses were performed for sertraline and N-desmethylsertraline, and CYP2D6 phenotyping was completed with dextromethorphan.

Results: Thirty-one participants (16 HIV(-), $12 \mathrm{Pl} / \mathrm{r}$, and $3 \mathrm{EFV}$ ) had median (range) weight, age, and dose of 69.5 (31.5-118.2) kg, 21.8 (9.1-24.7) years, and 75.0 (12.5150.0) mg once daily. Sertraline exposure was highest for HIV(-) and lowest for EFV cohorts; median dose-normalized $A \cup C_{0-24}$ was 1176 (HIV (-)), 791 (PI/r) and 473 (EFV) $\mathrm{ng} * \mathrm{hr} / \mathrm{mL}$, and $\mathrm{C}_{24}$ was $32.7(\mathrm{HIV}(-))$, $20.1(\mathrm{Pl} / \mathrm{r})$, and $12.8(\mathrm{EFV}) \mathrm{ng} / \mathrm{mL}$. The urinary dextromethorphan/dextrorphan (DXM/DXO) ratio was higher in $\mathrm{HIV}(-)$ vs. PI/r cohorts $(p=0.01)$. Four HIV $(-)$ participants were CYP2D6 poor metabolizers (In(DXM/DXO) of $>-0.5)$.

Conclusions: $H I V(-)$ cohort had the highest sertraline exposure. Sertraline exposure was $\sim 40 \%$ lower in the $\mathrm{Pl} / \mathrm{r}$ cohort than in $\mathrm{HIV}(-)$; the need to alter sertraline dose ranges for $\mathrm{Pl} / \mathrm{r}$ participants is not clear. The impact of efavirenz on sertraline needs further investigation due to limited numbers of EFV participants.

Keywords: sertraline, pharmacokinetics, HIV, pediatrics, antiretrovirals 


\section{INTRODUCTION}

The lifetime prevalence of major depression in patients with human immunodeficiency virus (HIV) is $22-45 \%$ (1), far exceeding the general population. Youth living with HIV are four times as likely to be treated with anti-depressant medication than uninfected youth (2). Two meta-analyses demonstrated a strong correlation between severity of depression and non-adherence to antiretroviral therapy $(3,4)$. Therefore, standard practice is to treat patients living with HIV and comorbid psychiatric conditions with psychotropic medications, despite a lack of adequate evidence regarding the risks. Psychiatric medications are often titrated to effectiveness. However, the typical starting dose and titration range may need to be adjusted in special populations (e.g., HIV and pediatrics) to produce exposures that have shown efficacy and tolerability in standard patient populations lacking comorbid conditions and interacting drugs.

Sertraline, a commonly used antidepressant, has an elimination half-life of about $27 \mathrm{~h}$ in adults, children, and adolescents (5). Sertraline undergoes extensive metabolism by cytochrome P450 (CYP) enzymes, CYP2B6, CYP2C9, CYP2C19, CYP2D6, and CYP3A4 (6, 7). N-demethylation forms $\mathrm{N}$-desmethylsertraline, the major inactive metabolite. $\mathrm{N}$-desmethylsertraline has an elimination half-life of 62$104 \mathrm{~h}$ (5). Genetic differences in metabolic pathways can lead to interpatient variability, with higher exposures in poor metabolizers and lower exposures in extensive metabolizers. A rough estimate of CYP2D6 intrinsic activity can be determined by administering a single dose of dextromethorphan and measuring the extent of metabolite (dextrorphan) formation compared to parent compound (a CYP2D6 phenotype assessment). Based on concentration ratio results, patients can be classified as either extensive or poor metabolizers. Numerous antiretrovirals are metabolized by and modulators of many of these same biotransformation pathways.

Ritonavir, a protease inhibitor and pharmacokinetic booster of other antiretrovirals, inhibits CYP3A4, the efflux transporter P-glycoprotein, and to a lesser extent, CYP2D6 $(8,9)$. However, at typical ritonavir boosting doses (100 mg), CYP2D6 inhibition is not clinically relevant (8). Ritonavir also induces CYP1A2, $2 \mathrm{~B} 6,2 \mathrm{C} 9$, and $2 \mathrm{C} 19$, and the phase II uridine diphosphateglucuronosyltransferase (UGT) enzymes (10-12).

Efavirenz, a common component of first-line antiretroviral therapy regimens, is a strong inducer of CYP3A4 and 2B6 (13). Efavirenz also induces CYP 2C19 in extensive and intermediate metabolizers, but not in CYP 2C19 poor metabolizers (14). Efavirenz decreases sertraline exposure $\left(\mathrm{AUC}_{0-24}\right)$ by $\sim 40 \%$ in adults. The induction of CYP $3 \mathrm{~A} 4$ in particular, which has high concentrations in both hepatic and intestinal tissues, could contribute to decreased absorption through first-pass loss since sertraline is administered orally. Despite decreased sertraline exposure with efavirenz, no adjustment of starting dose is recommended (13).

In pediatric sertraline pharmacokinetic studies, sertraline exposure $\left(\mathrm{AUC}_{0-24}\right.$ and $\mathrm{C}_{\max }$ ) was $\sim 22 \%$ lower in children and adolescents when plasma concentration was adjusted for weight $(5,9) /$; other pharmacokinetic parameters were comparable to adults (15-19). In adolescents, sertraline kinetics are not linear; the half-life of sertraline shortens significantly $(26.7-15.3 \mathrm{~h})$ from single dose to steady-state (17). In addition, over a dose range of 50-200 mg, the half-life of sertraline at steady-state increases from $15.3-27.2 \mathrm{~h}(15,17)$. The non-linearity of sertraline kinetics becomes increasingly important in youth with complex diseases and interacting medications. The objective of this study was to determine sertraline pharmacokinetics in youth without HIV, or with HIV and taking either an efavirenz-based or a ritonavirboosted protease inhibitor-based regimen.

\section{MATERIALS AND METHODS}

International Maternal Pediatric Adolescent AIDS Clinical Trials Network (IMPAACT) P1080 was a multicenter, pilot study of psychiatric and antiretroviral medication concentrations in HIV1 -infected and uninfected youth. Target enrollment for the sertraline study arm was 45 participants $>6$ to $<25$ years of age. 45 participants had sufficient power to detect a $50 \%$ difference in apparent oral clearance $(\mathrm{CL} / \mathrm{F})$ among HIV-infected and uninfected cohorts, assuming a coefficient of variation of $30 \%$. Participants were divided into three cohorts: (1) HIV-uninfected (HIV (-)), (2) HIV-infected taking concomitant efavirenz (EFV), and (3) HIV-infected taking boosting ritonavir with a protease inihibitor $(\mathrm{PI} / \mathrm{r})$ : protease inhibitors could include atazanavir, darunavir, fosamprenavir, indinavir, lopinavir, saquinavir or tipranavir.

All participants gave signed informed consent or assent, and parents or guardians gave signed informed permission in accordance with the Declaration of Helsinki and local guidelines. The protocol was approved by human subjects' protection committees or institutional review boards at each participating site (see Acknowledgments for a listing of participating sites). Participants took sertraline for clinical care for at least 2 weeks prior to enrollment. Participants who were pregnant or taking interacting illicit drugs were excluded.

Study procedures were standardized across multiple study arms. The single pharmacokinetic visit included a medication history, adherence survey, and a CYP2D6 phenotype assessment (the other psychotropic study medications were primarily metabolized by CYP 2D6). Participants with HIV had to be taking their antiretroviral medications consistently for at least 4 weeks prior to sampling. The visit was scheduled so that a witnessed dose of sertraline and antiretroviral medications occurred on time, according to the participant's dosing regimen. Plasma samples were drawn at pre-dose and 2, 4, 6, 12, and 24-h post-dose.

A liquid chromatography-electrospray ionization-mass spectrometry method quantitated sertraline and $\mathrm{N}$ desmethylsertraline. Isotope-labeled sertraline was used as an internal standard. Analytes and internal standard were extracted with $600 \mu \mathrm{L}$ of acetonitrile from $200 \mu \mathrm{L}$ of plasma, then eluted from a Gemini C18 column in under 4 min using acetonitrile/water/formic acid (85:15:0.1, v/v/v) as the mobile phase. Quantitation was performed with selective reaction monitoring of the transitions of $\mathrm{m} / \mathrm{z} 306.2 \rightarrow 159.1$ for sertraline, 
$292.2 \rightarrow 275$ for $\mathrm{N}$-desmethylsertraline, and $309.2 \rightarrow 159.1$ for internal standard. The method was linear over the concentration range of 1-320 ng/mL for both parent and metabolite.

The ratio of dextromethorphan (DXM)/dextrorphan (DXO) in urine was measured using a validated LC-MS/MS method following a single oral dose of dextromethorphan cough syrup $(15 \mathrm{mg}$ for participants $\geq 6$ to $<12$ years old; $30 \mathrm{mg}$ for participants $\geq 12$ to $<25$ years old). Poor metabolizer phenotype was defined as urinary DXM/DXO molar ratios $>0.3$ or $\log$ ratios $>-0.5$, while extensive metabolizer phenotype was defined as molar ratios $\leq 0.3$ or log ratios $\leq-0.5$.

Plasma concentrations of primary protease inhibitors, ritonavir and efavirenz were measured at the University of California San Diego Pediatric Pharmacology Laboratory by validated reverse phase high performance liquid chromatography or mass spectrometry methods. The interassay coefficients of variation were all $<18 \%$, and the mean recovery from the plasma ranged from 98 to $117 \%$. The lower limits of quantitation were: $0.047 \mu \mathrm{g} / \mathrm{mL}$ for atazanvir, $0.090 \mu \mathrm{g} / \mathrm{mL}$ for darunavir, $0.091 \mu \mathrm{g} / \mathrm{mL}$ for lopinavir, $0.094 \mu \mathrm{g} / \mathrm{mL}$ for ritonavir, and $0.039 \mu \mathrm{g} / \mathrm{mL}$ for efavirenz.

Plasma concentration at pre-dose $\left(\mathrm{C}_{0}\right)$, the maximum concentration $\left(\mathrm{C}_{\max }\right)$, the corresponding time $\left(\mathrm{t}_{\max }\right)$, and the concentration at $24 \mathrm{~h}$ post-dose $\left(\mathrm{C}_{24}\right)$ were identified by direct inspection of concentration-time curves. The area under the concentration vs. time curve from time $0-24 \mathrm{~h}$ post dose $\left(\mathrm{AUC}_{0-24}\right)$ was estimated using the trapezoidal rule. Apparent oral clearance (CL/F), where $\mathrm{F}$ is bioavailability, was calculated as dose divided by $\mathrm{AUC}_{0-24}$. The apparent volume of distribution $(\mathrm{V} / \mathrm{F}$ ) was determined as CL/F divided by $\mathrm{k}$, where $\mathrm{k}$ is the terminal slope of the log plasma concentrationtime curve. The half-life $\left(t_{1 / 2}\right)$ was calculated as $0.693 / \mathrm{k}$. All concentration data were normalized to dose $(100 \mathrm{mg})$ and to weight $(70 \mathrm{~kg})$. Non-compartmental parameters were estimated with Phoenix ${ }^{\circledR}$ WinNonlin ${ }^{\circledR}$ (Certara L.P. (Pharsight), St. Louis, MO). Pharmacokinetic parameters were compared between $\mathrm{HIV}(-)$ and $\mathrm{PI} / \mathrm{r}$ cohorts with Wilcoxon rank-sum tests, two-sided with significance set to 0.05. Statistical comparisons were not made with the EFV group due to the low enrollment/accrual in this cohort $(n=3)$.

Sertraline population pharmacokinetics were evaluated using non-linear mixed-effects modeling (NONMEM, version 7.4). A one-compartment model at steady-state with first-order absorption and elimination best described the data (ADVAN2 TRANS2, FOCE with interaction). A combined (additive and proportional) residual error model was used. Covariates were screened individually on each pharmacokinetic parameter $(\mathrm{CL} / \mathrm{F}$, $\mathrm{V} / \mathrm{F}$, and $\mathrm{k}_{\mathrm{a}}$ ). For all models, goodness of fit were assessed with diagnostic plots. All covariates that improved model fit at $p<0.05$ were included in the multivariate screen. The multivariate screen removed one covariate at a time, until every combination of covariates that were significant in the univariate screen were tested; covariates were retained if, when removed from the model, the model significantly worsened at $p<0.01$.

\section{RESULTS}

Thirty-one participants completed pharmacokinetic visits ( $n=16 \mathrm{HIV}(-) ; n=3 \mathrm{EFV} ; n=12 \mathrm{PI} / \mathrm{r}: 5$ on atazanavir/ritonavir, 5 on darunavir/ritonavir, and 2 on lopinavir/ritonavir). The median weight and height of participants on the day of sampling were $69.5 \mathrm{~kg}$ and $167.2 \mathrm{~cm}$, respectively (Table 1). The median age was 21.8 years (range 9-24.7). Participants' daily sertraline doses ranged from 12.5 to $150 \mathrm{mg}$. Median weight-normalized dose in $\mathrm{HIV}(-)(1.3 \mathrm{mg} / \mathrm{kg})$ was higher than in both the $\mathrm{PI} / \mathrm{r}$ and EFV groups (0.9 and $0.7 \mathrm{mg} / \mathrm{kg}$; Table 1$)$. A total of 181 plasma concentrations were measured. Two participants did not return for their 24-h time points, while three participants took their next dose of sertraline prior to the 24-h blood draw. Pharmacokinetics were estimated based on the pre-dose through $12 \mathrm{~h}$ post-dose concentrations for these participants.

Median normalized $\mathrm{AUC}_{0-24}$ values were 1176, 791, and 473 $\mathrm{ng} \cdot \mathrm{h} / \mathrm{mL}$ for HIV(-), PI/r and EFV cohorts, respectively (Table 2 and Figure 1). Non-compartmental oral CL/F were not different in the $\mathrm{HIV}(-)$ and $\mathrm{PI} / \mathrm{r}$ groups $(1.4$ vs. $1.6 \mathrm{~L} / \mathrm{h} / \mathrm{kg}, p=0.59)$. However, CL/F was markedly higher in the $\mathrm{EFV}$ group (4.5 $\mathrm{L} / \mathrm{h} / \mathrm{kg}$ ). Of $\mathrm{C}_{0}, \mathrm{C}_{\max }$, and $\mathrm{C}_{24}$, only $\mathrm{C}_{0}$ was significantly higher in the $\mathrm{HIV}(-)$ compared to the $\mathrm{PI} / \mathrm{r}$ cohorts (unadjusted and dose-normalized, $p=0.03$ ).

Sertraline typical population pharmacokinetic values for CL/F, $\mathrm{V} / \mathrm{F}$, and $\mathrm{k}_{\mathrm{a}}$ were estimated for the structural base model at 4.77 $\mathrm{L} / \mathrm{hr} / \mathrm{kg}^{0.75}, 53.8 \mathrm{~L} / \mathrm{kg}$, and $0.45 \mathrm{hr}^{-1}$ respectively (Table 3 ). The final population model (objective function decreased by 8.053 compared to the base model), which included the effect of age on clearance, resulted in estimated population values for $\mathrm{CL} / \mathrm{F}, \mathrm{V} / \mathrm{F}$, and $\mathrm{k}_{\mathrm{a}}$ of $4.35 \mathrm{~L} / \mathrm{hr} / \mathrm{kg}^{0.75}, 44.6 \mathrm{~L} / \mathrm{kg}$, and $0.42 \mathrm{hr}^{-1}$.

Median normalized $\mathrm{N}$-desmethylsertraline $\mathrm{AUC}_{0-24}$ in the $\mathrm{PI} / \mathrm{r}$ group was significantly lower than in the $\mathrm{HIV}(-)$ group (899 vs. $1,533 \mathrm{ng} \cdot \mathrm{h} / \mathrm{mL}, \quad p=0.01$; Table 2 and Figure 1). Following normalization, median $\mathrm{C}_{\max }$ in $\mathrm{HIV}(-)$ was

TABLE 1 | Participant demographics, Median (Interquartile Range)a .

\begin{tabular}{lccc}
\hline & HIV(-) & PI/r & EFV \\
& $(n=16)$ & $(n=12)$ & $(n=3)$ \\
Weight (kg) & $65(58,77)$ & $73(69,77)$ & $58(45,82)$ \\
Height (cm) & $166(163,172)$ & $169(165,175)$ & $152(145,165)$ \\
Weight Normalized & $1.3(0.9,1.5)$ & $0.9(0.6,1.4)$ & $0.7(0.6,1.1)$ \\
Daily Dose (mg/kg) & & & \\
Age (years) & $22.8(18.2,23.3)$ & $21.8(20.9,22.7)$ & $19.3(14.2,19.5)$ \\
SEX (\%) & $10(62.5)$ & $8(66.7)$ & $2(66.7)$ \\
Female & $6(37.5)$ & $4(33.3)$ & $1(33.3)$ \\
Male & & & \\
RACE (\%) & $1(6.2)$ & $0(0.0)$ & $0(0.0)$ \\
American Indian & $1(6.2)$ & $0(0.0)$ & $0(0.0)$ \\
Asian & $2(12.5)$ & $11(91.7)$ & $2(66.7)$ \\
Black & $0(0.0)$ & $1(8.3)$ & $0(0.0)$ \\
Unknown & $12(75.0)$ & $0(0.0)$ & $1(33.3)$ \\
White & & & \\
\hline
\end{tabular}

${ }^{a}$ For the EFV cohort, median (minimum, maximum) are reported. 
TABLE 2 | Sertraline and N-desmethylsertraline pharmacokinetic parameters, median (Interquartile Range)a .

\begin{tabular}{|c|c|c|c|c|}
\hline Parameter & $\mathrm{HIV}(-) n=16$ & $\mathrm{PI} / \mathrm{r} n=12$ & $p$-value ${ }^{b}$ & $\mathrm{EFV} n=3$ \\
\hline \multicolumn{5}{|l|}{ SERTRALINE } \\
\hline$A \cup C_{0-24}\left(\mathrm{ng}^{*} \mathrm{hr} / \mathrm{mL}\right)$ & $652(506,1407)$ & $486(415,670)$ & 0.08 & $145(138,286)$ \\
\hline Norm-AUC $0-24\left(\mathrm{ng}^{\star} \mathrm{hr} / \mathrm{mL}\right)^{\mathrm{C}}$ & $1176(713,1890)$ & $791(546,961)$ & 0.12 & $473(374,614)$ \\
\hline$C_{0}(\mathrm{ng} / \mathrm{mL})$ & $20.1(12.6,39.7)$ & $10.0(7.5,15.9)$ & 0.03 & $6.0(3.0,7.0)$ \\
\hline Norm- $C_{0}(\mathrm{ng} / \mathrm{mL})^{\mathrm{c}}$ & $33.3(17.6,57.3)$ & $17.8(9.9,23.0)$ & 0.03 & $13.1(9.2,19.6)$ \\
\hline$C_{\max }(\mathrm{ng} / \mathrm{mL})$ & $46.7(36.5,90.1)$ & $34.3(23.6,41.7)$ & 0.09 & $13.2(8.8,22.1)$ \\
\hline Norm- $C_{\max }(\mathrm{ng} / \mathrm{mL})^{\mathrm{c}}$ & $78.3(50.9,110.7)$ & $46.9(42.2,68.7)$ & 0.06 & $28.8(28.4,58.7)$ \\
\hline$T_{\max }(\mathrm{hr})$ & $4(4,6)$ & $4(4,6)$ & 1.00 & $6(4,6)$ \\
\hline $\mathrm{C}_{24}(\mathrm{ng} / \mathrm{mL})$ & $17.5(14.3,40.1)$ & $12.6(8.6,18.9)$ & 0.07 & $4.2(2.9,5.9)$ \\
\hline Norm- $C_{24}(\mathrm{ng} / \mathrm{mL})^{\mathrm{c}}$ & $32.7(17.6,51.9)$ & $20.1(11.8,29.2)$ & 0.17 & $12.8(7.6,13.8)$ \\
\hline$C L / F(L / h r / k g)$ & $1.4(0.8,2.3)$ & $1.6(1.2,2.3)$ & 0.59 & $4.5(1.6,11.5)$ \\
\hline$T_{1 / 2}(\mathrm{hr})$ & $26.4(14.1,35.3)$ & $18.1(12.5,23.1)$ & 0.28 & $11.1(10.2,20.7)$ \\
\hline AUC Ratio (DSRT/SRT) & $1.4(1.2,1.7)$ & $1.3(0.7,1.6)$ & 0.13 & $2.2(2.1,2.6)$ \\
\hline $\operatorname{Ln}(D X M / D X O)^{d}$ & $-2.3(-3.0,-0.6)$ & $-4.3(-4.8,-3.8)$ & 0.01 & -2.35 \\
\hline \multicolumn{5}{|l|}{ N-DESMETHYLSERTRALINE } \\
\hline$A \cup C_{0-24}\left(\mathrm{ng}^{*} \mathrm{hr} / \mathrm{mL}\right)$ & $1063(848,1721)$ & $670(230,1244)$ & 0.09 & $376(293,624)$ \\
\hline Norm-AUC $0-24\left(\mathrm{ng}^{\star} \mathrm{hr} / \mathrm{mL}\right)^{\mathrm{C}}$ & $1533(1053,2133)$ & $899(646,1186)$ & 0.01 & $1223(814,1301)$ \\
\hline$C_{0}(\mathrm{ng} / \mathrm{mL})$ & $41.7(29.2,65.8)$ & $17.8(4.8,43.1)$ & 0.05 & $15.5(7.6,25.5)$ \\
\hline Norm- $C_{0}(\mathrm{ng} / \mathrm{mL})^{\mathrm{C}}$ & $50.6(33.5,100.9)$ & $23.8(11.7,45.0)$ & 0.01 & $33.7(33.2,50.3)$ \\
\hline$C_{\max }(\mathrm{ng} / \mathrm{mL})$ & $56.3(45.6,92.0)$ & $34.4(12.5,57.6)$ & 0.07 & $17.5(16.8,34.1)$ \\
\hline Norm- $C_{\max }(\mathrm{ng} / \mathrm{mL})^{\mathrm{c}}$ & $76.6(54.1,138.7)$ & $44.6(33.1,58.8)$ & 0.01 & $56.8(44.5,74.7)$ \\
\hline $\mathrm{C}_{24}(\mathrm{ng} / \mathrm{mL})$ & $40.8(30.4,68.3)$ & $20.5(10.3,45.1)$ & 0.07 & $15.2(8.7,20.8)$ \\
\hline Norm- $C_{24}(\mathrm{ng} / \mathrm{mL})^{\mathrm{c}}$ & $59.4(36.6,82.0)$ & $33.6(17.8,56.4)$ & 0.03 & $38.7(27.1,49.3)$ \\
\hline
\end{tabular}

${ }^{a}$ For the EFV cohort, median (minimum, maximum) are reported.

${ }^{b} p$-values calculated using the Wilcoxon rank-sum test for HIV(-) and PI/r comparisons.

${ }^{c}$ Normalized to a $100 \mathrm{mg}$ once daily dose and a weight of $70 \mathrm{~kg}$.

${ }^{d}$ Urine DXM/DXO ratio was measured in 12 HIV(-), 6 PI/r, \& 1 EFV.

statistically higher than $\mathrm{PI} / \mathrm{r}$ (76.6 vs. $44.6 \mathrm{ng} / \mathrm{mL}, p=0.01$ ). Following normalization, $\mathrm{C}_{0}$ and $\mathrm{C}_{24}$ in $\mathrm{HIV}(-)$ were statistically greater than $\mathrm{PI} / \mathrm{r}(50.6$ vs. $23.8 \mathrm{ng} / \mathrm{mL}, p=0.01 ; 59.4$ vs. $33.6 \mathrm{ng} / \mathrm{mL}, p=0.03)$.

Median (interquartile range) ritonavir $\mathrm{AUC}_{0-12}$ and $\mathrm{C}_{\max }$ for $\mathrm{PI} / \mathrm{r}$ participants were $4.9(3.0,9.4) \mu \mathrm{g} \cdot \mathrm{h} / \mathrm{mL}$ and $0.6(0.4,1.6)$ $\mu \mathrm{g} / \mathrm{mL}$ (Table 4). Median (range) efavirenz $\mathrm{AUC}_{0-24}$ and $\mathrm{C}_{\max }$ for the three EFV participants were $24.5(24.4,68.2) \mu \mathrm{g} \cdot \mathrm{h} / \mathrm{mL}$ and $1.3(1.3,3.4) \mu \mathrm{g} / \mathrm{mL}$. No relationship was observed between ritonavir $\mathrm{AUC}_{0-12}$ and dose normalized sertraline $\mathrm{AUC}_{0-24}$ $\left(r^{2}=0.005\right)$ or ritonavir $\mathrm{AUC}_{0-12}$ and the $\mathrm{AUC}_{0-24}$ ratio of N-desmethylsertraline/sertraline $\left(r^{2}=0.09\right)$. No correlation was present between efavirenz $\mathrm{AUC}_{0-24}$ and dose-normalized sertraline $\mathrm{AUC}_{0-24}\left(r^{2}=0.01\right)$. A correlation was present between efavirenz $\mathrm{AUC}_{0-24}$ and the $\mathrm{AUC}_{0-24}$ ratio of $\mathrm{N}$ desmethylsertraline/sertraline $\left(r^{2}=0.97\right)$. However, with a small sample size $(n=3)$, these results should be interpreted with caution.

Metabolic phenotyping was performed in 19 of 31 participants (12 HIV(-), $6 \mathrm{PI} / \mathrm{r}$, and $1 \mathrm{EFV}$ ). The log ratio of DXM to DXO in the HIV (-) group was significantly higher than the PI/r group ( -2.3 vs. $-4.3, p=0.01)$. Four of twelve participants in the HIV() group were CYP2D6 poor metabolizers, compared to zero of six $\mathrm{PI} / \mathrm{r}$ participants. CYP2D6 phenotype was tested as a covariate on the sertraline population pharmacokinetic model, but did not significantly affect $\mathrm{CL} / \mathrm{F}$ or $\mathrm{V} / \mathrm{F}$.

\section{DISCUSSION}

This is the first report of sertraline pharmacokinetics among youth living with HIV. Sertraline and N-desmethylsertraline exposure parameters trended lower or were significantly lower in the PI/r compared to the HIV(-) groups. Sertraline exposure, corrected for weight and dose, was much lower in EFV participants, but the sample size was very small. Few patients with psychiatric conditions were taking efavirenz, likely due to clinician concerns about central nervous system side effects associated with efavirenz use in patients with psychiatric disorders. The normalized sertraline $\mathrm{AUC}_{0-24}$ in the $\mathrm{HIV}(-)$ group $(1,176 \mathrm{ng} \cdot \mathrm{hr} / \mathrm{mL})$ was similar to that seen after multiple dosing in prior adult studies, normalized to a $100 \mathrm{mg}$ dose (1038-1532 $\mathrm{ng} \cdot \mathrm{hr} / \mathrm{mL})(20)$. The normalized sertraline trough concentrations, $\mathrm{C}_{0}$ and $\mathrm{C}_{24}$, in the $\mathrm{HIV(-)}$ and $\mathrm{PI} / \mathrm{r}$ groups of approximately $18-33 \mathrm{ng} / \mathrm{mL}$ were also similar to those in a therapeutic drug monitoring program, that reported a median and IQR sertraline trough with $100 \mathrm{mg}$ daily doses of $20 \mathrm{ng} / \mathrm{mL}$ and $12-30 \mathrm{ng} / \mathrm{mL}$ (21). The observed troughs in the EFV group 

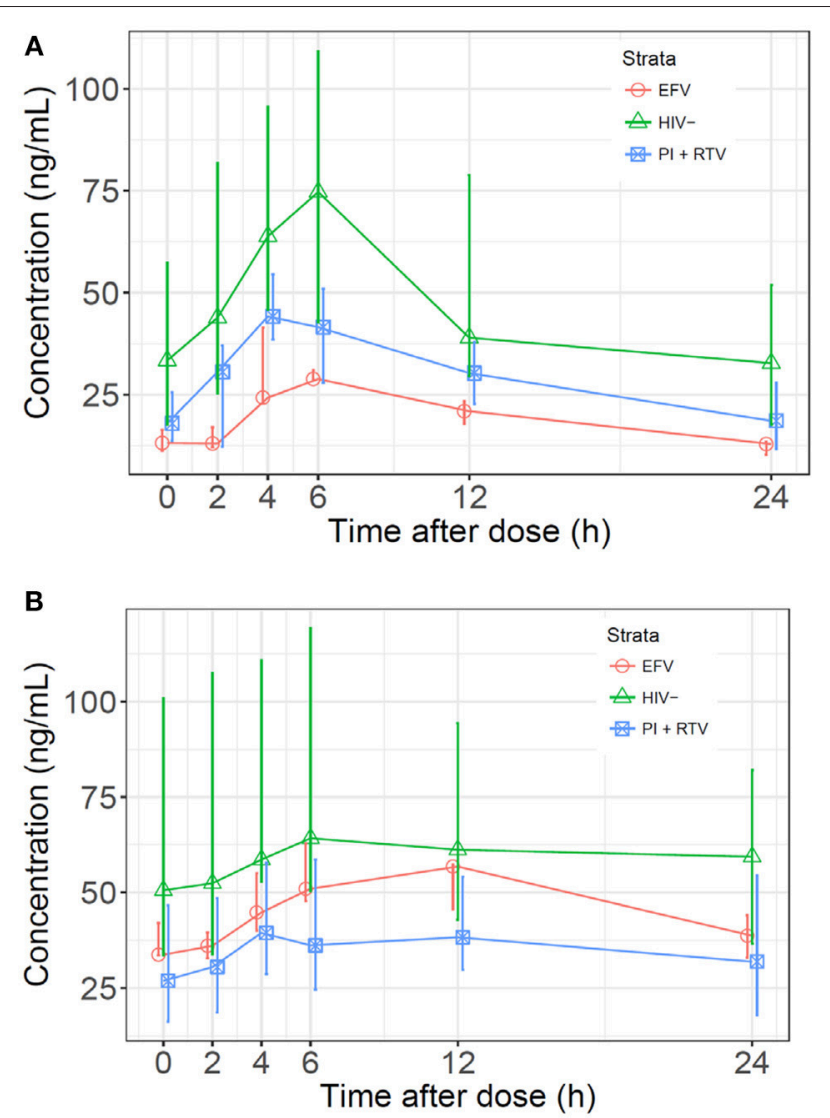

FIGURE 1 | (A) Median sertraline profiles by cohort. Sertraline concentrations were normalized to a dose of $100 \mathrm{mg}$ and a patient weight of $70 \mathrm{~kg}$. (B) Median N-desmethylsertraline profiles by cohort. Concentrations were normalized to a sertraline dose of $100 \mathrm{mg}$ and a patient weight of $70 \mathrm{~kg}$.

of 4.2 and $6 \mathrm{ng} / \mathrm{mL}$ were well below these typical trough values. The median weight-adjusted daily dose $(\mathrm{mg} / \mathrm{kg})$ in the HIV(-) group, while not statistically different, was higher than both groups of participants living with HIV. This suggests that clinicians are dosing sertraline more conservatively, possibly due to concerns about interacting antiretrovirals, in youth living with HIV. However, weight- and dose-normalized sertraline $\mathrm{AUC}_{0-24}$ suggests that youth taking common PI/r should be receiving equivalent, or potentially higher, weight-adjusted doses as their HIV-uninfected peers.

While we expected normalized sertraline exposures to be greater in HIV(-) vs. EFV participants, due to strong cytochrome P450 induction, we did not expect to also observe lower sertraline in $\mathrm{PI} / \mathrm{r}$ participants. Sertraline is eliminated by multiple pathways including CYP2B6, CYP2D6, CYP2C9, CYP2C19, and CYP3A4. Ritonavir is a strong inhibitor of CYP2D6 and CYP3A4, but is also a strong inducer of CYP2C19 and UGT, a phase II metabolic pathway of sertraline (7). Involvement of numerous enzymes in sertraline metabolism make it unlikely for one agent to cause a clinically significant drug interaction $(7,20)$. Antiretroviral exposures in this study were similar to expected values, suggesting that participants were adherent to antiretrovirals. Our results, lower normalized (weight/dose) sertraline and $\mathrm{N}$-desmethylsertraline $\mathrm{AUC}_{0-24}$ and the AUC ratio (N-desmethylsertraline/sertraline) in $\mathrm{PI} / \mathrm{r}$ vs. $\mathrm{HIV}(-)$ participants, suggest that inhibition of various CYP enzymes by ritonavir does not increase sertraline exposure. Furthermore, decreased sertraline exposures in $\mathrm{PI} / \mathrm{r}$ relative to $\mathrm{HIV}(-)$ were not a consequence of induction of enzymatic pathways, since ritonavir $\mathrm{AUC}_{0-24}$ did not correlate with the $\mathrm{N}$-desmethylsertraline/sertraline AUC ratio. If induction was present, the AUC ratio would increase with increasing ritonavir. The most likely explanations for reduced sertraline exposures in the PI/r cohort are (1) decreased drug absorption in participants living with HIV and (2) lower sertraline doses prescribed (which can cause changes in sertraline pharmacokinetics that are not proportional to the difference in dose amount).

Another potential contributing factor to sertraline exposure differences could be underlying genetic polymorphisms in CYP enzymes. The Clinical Pharmacogenetics Implementation Consortium recommends a 50\% decrease in sertraline dose in CYP 2C19 poor metabolizers due to increased adverse effects, but no change in dose for ultrarapid metabolizers. This recommendation is optional due to limited available evidence (22). CYP 2C19 genotypes of study participants were not determined.

A population pharmacokinetic study of geriatric patients (median age $=76$ years) with Alzheimer's Disease also determined a 1-compartment model with first-order absorption and elimination best described sertraline, and estimated a clearance of $83.1 \mathrm{~L} / \mathrm{h}$ (23). Our study estimated clearance at $115 \mathrm{~L} / \mathrm{h}$ (for a typical $70 \mathrm{~kg}$ patient); $38 \%$ higher. In our model, of the covariates tested on $\mathrm{CL} / \mathrm{F}$ and $\mathrm{V} / \mathrm{F}$ (age, gender, race, cohort, CYP2D6 phenotype, aspartate aminotransferase, alanine aminotransferase, serum creatinine, and AUC ratio (N-desmethylsertraline/sertraline)), only age (independent of size) significantly affected clearance. This finding contrasts with previous pediatric studies and the aforementioned geriatric study, which found no associations between age and sertraline pharmacokinetics. Our finding should be interpreted with caution due to the limited range of ages in this study, 14-23 years. Gender did not affect sertraline pharmacokinetics in our study, similar to prior pediatric trials, but different from adults where men had an elimination half-life approximately 1.5 times greater than women (19).

EFV participants had sertraline exposures $~ 50 \%$ lower than $\mathrm{HIV}(-)$ and PI/r groups. In previous pediatric studies $(15,17)$, $\mathrm{AUC}_{0-24}$ (normalized to $100 \mathrm{mg}$ dose and $70 \mathrm{~kg}$ weight) ranged from 883 to $2,535 \mathrm{ng} \cdot \mathrm{h} / \mathrm{mL}$, much higher than $473 \mathrm{ng} \cdot \mathrm{h} / \mathrm{mL}$ in the EFV group. The metabolite-to-parent AUC ratio was approximately $50 \%$ higher in EFV than other cohorts, and efavirenz AUC was correlated with metabolite-to-parent AUC ratio $\left(r^{2}=0.97\right)$. These findings suggest that participants taking efavirenz have a much higher oral intrinsic clearance, possibly through induction of multiple CYP enyzmes that contribute to sertraline metabolism, including 2B6, 2C19, and 3A4. For 3A4 in particular, the reduction in EFV exposure could be due to induction at the intestinal level along with hepatic induction, 
TABLE 3 | Base \& final population pharmacokinetic parameters ${ }^{a}$.

\begin{tabular}{|c|c|c|c|c|}
\hline Parameters & Base model & Estimate (\% SE) & Final model & Estimate ( $\%$ SE) \\
\hline$C L / F\left(L / h r / k^{0.75}\right)$ & $\theta_{1}{ }^{\star} \mathrm{ALWT}{ }^{0.75} \exp \left(\eta_{1}\right)$ & $4.77(12)$ & $\begin{array}{l}\theta_{1}{ }^{*} \mathrm{ALWT} \mathrm{T}^{0.75} \exp \left(\eta_{1}\right) \\
{ }^{*}\left((\mathrm{Age} / 21.8) \exp \left(\theta_{4}\right)\right)\end{array}$ & 4.35 (10.6) \\
\hline V/F (L/kg) & $\theta_{2}{ }^{*} \mathrm{WT}$ & $53.8(20.1)$ & $\theta_{2}{ }^{*} \mathrm{WT}$ & $44.6(10.3)$ \\
\hline ka (1/h) & $\theta_{3}$ & 0.45 (16.2) & $\mathrm{k}+\theta_{3}$ & $0.42(14.7)$ \\
\hline
\end{tabular}

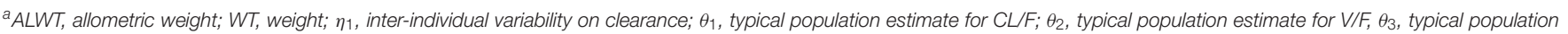
estimate for ka. K, elimination rate constant.

TABLE 4 | Antiretroviral exposures, median (Interquartile range) ${ }^{\mathrm{a}}$.

\begin{tabular}{lcccc}
\hline & $n$ & $A \cup C_{0-\operatorname{tau}}\left(\mu \mathrm{g}^{\star} \mathrm{hr} / \mathrm{mL}\right)$ & $C_{\max }(\mu \mathrm{g} / \mathrm{mL})$ & $C_{\text {last }}(\mu \mathrm{g} / \mathrm{mL})$ \\
\hline ANALYTE & & & & \\
Atazanavir & 5 & $27.2(21.8,38.7)$ & $3.8(3.1,5.2)$ & $1.2(0.9,2.6)$ \\
Darunavir & 5 & $60.1(50.2,66.5)$ & $6.8(6.2,7.1)$ & $3.5(3.2,3.9)$ \\
Lopinavir & 2 & $41.6,62.0$ & $11.9,4.9$ & $2.4,3.5$ \\
Ritonavir & 12 & $4.9(3.0,9.4)$ & $0.6(0.4,1.6)$ & $0.2(0.1,0.4)$ \\
Efavirenz & 3 & $24.5(24.4,68.2)$ & $1.3(1.1,3.4)$ & $1.3(1.3,3.4)$ \\
\hline
\end{tabular}

a The range is reported for lopinavir and the median (range) is reported for efavirenz.

resulting in both increased systemic clearance and decreased absorption due to first-pass loss upon oral administration. A larger sample size is needed to confirm this observation.

Participants in the HIV(-) group had sertraline weightadjusted pharmacokinetic characteristics similar to adults. Ensuring dose modifications according to weight are therefore necessary for youth without HIV to achieve similar therapeutic exposures. Sertraline exposure in the PI/r cohort was $30-40 \%$ lower compared to $\operatorname{HIV}(-)$. Concomitant ritonavir did not increase sertraline exposure as it does with many other medications, and youth taking a ritonavir-boosted protease inhibitor should be receiving at least the same sertraline dose $(\mathrm{mg} / \mathrm{kg})$, or potentially even modestly higher doses, as uninfected youth and adults. Participants taking efavirenz had much lower sertraline exposures than the two other cohorts and adults. Even though psychiatric medications are often titrated to effect, these participants did not receive higher absolute or weight-adjusted doses than the other groups, and likely had sub-therapeutic exposures. Caution should be exercised when interpreting findings from the EFV cohort due to the small sample size $(n=3)$, but higher doses or therapeutic drug monitoring of sertraline in this population may be warranted.

\section{DATA AVAILABILITY STATEMENT}

The data cannot be made publicly available due the ethical restrictions in the study's informed consent documents and in the International Maternal Pediatric Adolescent AIDS Clinical Trials (IMPAACT) Network's approved human subjects protection plan; public availability may compromise participant confidentiality. However, data are available to all interested researchers upon request to the IMPAACT Statistical and Data Management Center's data access committee (email address: sdac.data@fstrf.org) with the agreement of the IMPAACT Network.

\section{ETHICS STATEMENT}

All participants gave written informed consent, permission or assent in accordance with the Declaration of Helsinki and local guidelines. The protocol was approved by all relevant ethics or human subjects protection committees at all participating sites.

\section{AUTHOR CONTRIBUTIONS}

All co-authors reviewed, revised for content, and approved this article. MP, YH, SK, ES, GS, PB, EC, and BB: substantial contributions to the conception and design; $\mathrm{NH}, \mathrm{MP}, \mathrm{BG}$, and BJ: acquisition of data; $\mathrm{NH}, \mathrm{MP}, \mathrm{YH}, \mathrm{SK}, \mathrm{ES}, \mathrm{GS}, \mathrm{PB}, \mathrm{EC}$, and BB: analysis or interpretation of data.

\section{FUNDING}

Overall support for the International Maternal Pediatric Adolescent AIDS Clinical Trials Network (IMPAACT) was provided by the National Institute of Allergy and Infectious Diseases (NIAID) with co-funding from the Eunice Kennedy Shriver National Institute of Child Health and Human Development (NICHD) and the National Institute of Mental Health (NIMH), all components of the National Institutes of Health (NIH), under Award Numbers UM1AI068632 (IMPAACT LOC), UM1AI068616 (IMPAACT SDMC) and UM1AI106716 (IMPAACT LC), and by NICHD contract number HHSN275201800001I. NH was supported by NICHD T32 HD087978. The content is solely the responsibility of the authors and does not necessarily represent the official views of the NIH.

\section{ACKNOWLEDGMENTS}

We thank the participating reviewers, staff and sites: Sonia Lee, Ph.D.; Norma J. Cooper, MA, BSN, ACRN and Kathleen Pitts, RN, PNP-C, NNP, MPH (Texas Children's Hospital CRS); Ann J. Melvin, MD, MPH and Amanda Robson Nuss, BS (Seattle Children's Research Institute NICHD CRS); Thuy Anderson, $\mathrm{RN}$ and Aleisha Collinson-Streng, RN (Johns Hopkins Univ. Baltimore NICHD CRS); Stephen A. Spector, MD and Kimberly 
Norris, RN (University of California, UC San Diego CRS); Nehali Patel, MD and Sandra C. Jones, DNP, APN, CPNP (St. Jude Children's Research Hospital CRS); Richard M. Rutstein, MD and Sheri McDougall, MSHed (Philadelphia IMPAACT Unit

\section{REFERENCES}

1. Penzak SR, Reddy YS, Grimsley SR. Depression in patients with HIV infection. Am J Health Syst Pharm. (2000) 57:376-86. doi: 10.1093/ajhp/57.4.376

2. Chernoff M, Nachman S, Williams P, Brouwers P, Heston J, Hodge J, et al. Mental health treatment patterns in perinatally HIV-infected youth and controls. Pediatrics (2009) 124:627-36. doi: 10.1542/peds.2008-2441

3. Gonzalez JS, Batchelder AW, Psaros C, Safren SA. Depression and HIV/AIDS treatment nonadherence: a review and meta-analysis. J Acquir Immune Defic Syndr. (2011) 58:181-7. doi: 10.1097/QAI.0b013e31822d490a

4. Wagner GJ, Goggin K, Remien RH, Rosen MI, Simoni J, Bangsberg DR, et al. A closer look at depression and its relationship to HIV antiretroviral adherence. Ann Behav Med. (2011) 42:352-60. doi: 10.1007/s12160-011-9295-8

5. Pfizer Canada I. Zoloft Product Monograph. Kirkland, QC: Pfizer Canada, Inc., (2014).

6. Kobayashi K, Ishizuka T, Shimada N, Yoshimura Y, Kamijima K, Chiba K. Sertraline N-demethylation is catalyzed by multiple isoforms of human cytochrome P-450 in vitro. Drug Metab Dispos. (1999) 27:763-6.

7. Obach RS, Cox LM, Tremaine LM. Sertraline is metabolized by multiple cytochrome P450 enzymes, monoamine oxidases, and glucuronyl transferases in human: an in vitro study. Drug Metab Dispos. (2005) 33:262-70. doi: $10.1124 / \mathrm{dmd} .104 .002428$

8. KALETRA. Product Monograph. Kaletra (lopinavir/ritonavir). St Laurent, QC: AbbVie Corporation (2017).

9. Lee CG, Gottesman MM, Cardarelli CO, Ramachandra M, Jeang KT, Ambudkar SV, et al. HIV-1 protease inhibitors are substrates for the MDR1 multidrug transporter. Biochemistry (1998) 37:3594-01. doi: $10.1021 /$ bi972709x

10. Hogeland GW, Swindells S, McNabb JC, Kashuba AD, Yee GC, Lindley CM. Lopinavir/ritonavir reduces bupropion plasma concentrations in healthy subjects. Clin Pharmacol Ther. (2007) 81:69-75. doi: 10.1038/sj.clpt.61 00027

11. Hsu A, Granneman GR, Bertz RJ. Ritonavir. Clinical pharmacokinetics and interactions with other anti-HIV agents. Clin Pharmacokinet. (1998) 35:275-91. doi: 10.2165/00003088-19983504000002

12. Yeh RF, Gaver VE, Patterson KB, Rezk NL, Baxter-Meheux F, Blake MJ, et al. Lopinavir/ritonavir induces the hepatic activity of cytochrome P450 enzymes CYP2C9, CYP2C19, and CYP1A2 but inhibits the hepatic and intestinal activity of CYP3A as measured by a phenotyping drug cocktail in healthy volunteers. J Acquir Immune Defic Syndr. (2006) 42:52-60. doi: 10.1097/01.qai.0000219774.20174.64

13. Sustiva. Sustiva (package insert). Princeton, NJ: Bristol-Myers Squibb Company (2017)

14. Michaud V, Kreutz Y, Skaar T, Ogburn E, Thong N, Flockhart D, et al. Efavirenz-mediated induction of omeprazole metabolism is CYP2C19 genotype-dependent. Pharmacogenomics J. (2014) 14:151-9. doi: $10.1038 /$ tpj.2013.17
NICHD CRS); Dr. Ram Yogev, MD and Ruth Williams, RN (Lurie Children's Hospital of Chicago (LCH) CRS); Suzanne Paul BSN, MSN, RN, FNP-C and Kacey Navarro RN, BSN, FNP-C (Univ. of Colorado Denver NICHD CRS).
15. Alderman J, Wolkow R, Chung M, Johnston HF. Sertraline treatment of children and adolescents with obsessive-compulsive disorder or depression: pharmacokinetics, tolerability, and efficacy. J Am Acad Child Adolesc Psychiatry (1998) 37:386-94. doi: 10.1097/00004583-199804000-00016

16. Alderman J, Wolkow R, Fogel IM. Drug concentration monitoring with tolerability and efficacy assessments during open-label, long-term sertraline treatment of children and adolescents. J Child Adolesc Psychopharmacol. (2006) 16:117-29. doi: 10.1089/cap.2006.16.117

17. Axelson DA, Perel JM, Birmaher B, Rudolph GR, Nuss S, Bridge J, et al. Sertraline pharmacokinetics and dynamics in adolescents. J Am Acad Child Adolesc Psychiatry (2002) 41:1037-44. doi: 10.1097/00004583-200209000-00003

18. Taurines R, Burger R, Wewetzer C, Pfuhlmann B, Mehler-Wex C, Gerlach $\mathrm{M}$, et al. The relation between dosage, serum concentrations, and clinical outcome in children and adolescents treated with sertraline: a naturalistic study. Ther Drug Monit. (2013) 35:84-91. doi: 10.1097/FTD.0b013e31827alaad

19. Ronfeld RA, Tremaine LM, Wilner KD. Pharmacokinetics of sertraline and its $\mathrm{N}$-demethyl metabolite in elderly and young male and female volunteers. Clin Pharmacokinet. (1997) 32(Suppl. 1):22-30. doi: 10.2165/00003088-199700321-00004

20. DeVane CL, Liston HL, Markowitz JS. Clinical pharmacokinetics of sertraline. Clin Pharmacokinet. (2002) 41:1247-66. doi: 10.2165/00003088-200241150-00002

21. Jons L, Margareta R, Finn B. Therapeutic drug monitoring of sertraline: variability factors as displayed in a clinical setting. Therap Drug Monitor (2000) 22:446-54. doi: 10.1097/00007691-200008000-00014

22. Hicks JK, Bishop JR, Sangkuhl D, Muller DJ, Ji Y, Leckband SG, et al. Clinical pharmacogenetics implementation consortium (CPIC) guideline for CYP 2D6 and CYP 2C19 genotypes and dosing of selective serotonin reuptake inhibitors. Clin Pharmacol and Ther. (2015) 98:127-34. doi: 10.1002/ cpt. 147

23. Li CH, Pollock BG, Lyketsos CG, Vaidya V, Drye LT, Kirshner M, et al. Population pharmacokinetic modeling of sertraline treatment in patients with Alzheimer disease: the DIADS-2 study. J Clin Pharmacol. (2013) 53:234-9. doi: $10.1177 / 0091270012445793$

Conflict of Interest Statement: The authors declare that the research was conducted in the absence of any commercial or financial relationships that could be construed as a potential conflict of interest.

Copyright (c) 2019 Hanan, Paul, Huo, Kapetanovic, Smith, Siberry, Brouwers, Graham, Johnston, Capparelli and Best. This is an open-access article distributed under the terms of the Creative Commons Attribution License (CC BY). The use, distribution or reproduction in other forums is permitted, provided the original author(s) and the copyright owner(s) are credited and that the original publication in this journal is cited, in accordance with accepted academic practice. No use, distribution or reproduction is permitted which does not comply with these terms. 